\title{
Dispersion Change in Peat Mechanical Treatment
}

\author{
Vladimir Lebedev ${ }^{1, *}$, and Olga Puhova ${ }^{1}$ \\ ${ }^{1}$ Tver State Technical University, A. Nikitin Street 22, 170026, Tver, Russia
}

\begin{abstract}
The article discusses the research of peat physical and mechanical treatment which consists in determining technological parameters of peat stock. Size distribution and conditional specific surface area of peat particles are set. The relationship between processing efficiency and the content of peat fractions which size is less than 250 microns is derived. It proves to be linear. Treatment efficiency is found to be estimated by the data of a screen analysis alone and with satisfactory accuracy. Mechanical treatment has an effect on the values of total moisture capacity. The dependence is nonlinear and decreases insignificantly up to the conditional specific surface area of $350 \mathrm{~m}^{2} / \mathrm{kg}$ due to the partial grinding of fibrous coarse fractions. Mechanical treatment up to the conditional specific surface area of $500 \mathrm{~m}^{2} / \mathrm{kg}$ results in the sharp decrease of total moisture capacity due to the practically complete destruction of coarse fractions. With that of more than $500 \mathrm{~m}^{2} / \mathrm{kg}$ the values of total moisture capacity change insignificantly. Multiple peat treatment causes its mechanical consolidation and the reduction of coarse fraction content along with significant increase of fine fraction content.
\end{abstract}

\section{Introduction}

The flowsheet of the production of finished products from peat stock is based on the processes of its significant dewatering at various production stages and during mechanical treatment [1-7]. Totally water-saturated peat has water of weak bond, mechanical and osmotic retention. The maximal amount of water relative to dry weight which can be retained owing to different forces (molecular, osmotic) defines its total moisture capacity. The capacity characterizes the initial peat condition depending on its composition, peat decay degree, and acidity. The capacity to take up water is determined by the content of fibrous coarse particles having large cavities which absorb and retain large amounts of water. Physical and mechanical treatment condenses such cavities. Dispersed peat systems are characterized by the substance fineness factor expressed as a percentage and conditional specific surface area of particles. The latter should be defined to characterize peat as the raw stock for industry and to study different production processes.

The complete dispersion characteristic of peat is combined with three analyses: wet screen, sedimentometric, and electron microscopic [8-12]. However, electron microscopic results giving the size distribution in a colloidal area (the particle sizes being less than 1

\footnotetext{
* Corresponding author: oleg.misnikov@gmail.com
} 
micron) are negligible for technological purposes. Among the two first analyses the sedimentometric one is carried out with $76-85 \%$ of peat mass. Therefore, this kind of analysis is obviously critical for peat dispersion to be determined. The sedimentometric analysis is performed with an upgraded and advanced model of weight sedimentometer. The model is distinguished by the absence of a flat spring sometimes giving trouble to a sedimentometer operation and the use of a cup with a shortened rod hung on a thin thread which helps avoid evaporation interference. The novelty of the analysis management is as follows:

The results are managed during the analysis. A sound method of computing the settled particle percentage is used, the reliability of results being enhanced.

A detailed separation of particles into fractions is used, the accuracy of results increasing.

\section{Materials and Methods}

The research of physical and mechanical treatment of raw peat consists in determining its technological parameters and finished product quality factors such as dispersion, ash content, and acidity [13-16]. The physical and mechanical treatment of raw peat includes four dispersion options:

1) the mixing of peat in order to provide its uniformity - 'untreated peat' option

2) a single treatment on a screw conveyer operated manually

3) a three-fold treatment on the same screw conveyer

4) a ten-fold treatment on the same screw conveyer.

To standardize the preparation raw peat samples are shaken with water in a 1-1.5 liter flask for 5 minutes. Tables 1 and 2 show the results of the dispersion research for each option.

Table 1. Percentage of Peat Fractions.

\begin{tabular}{|c|c|c|}
\hline Fraction size, $\mathbf{m m}$ & Fraction weight, $\boldsymbol{P}_{\boldsymbol{i}}, \mathbf{g}$ & $\begin{array}{c}\text { Fraction content, } \\
\boldsymbol{P}_{\boldsymbol{i}} \mathbf{\%}\end{array}$ \\
\hline $7-3$ & 0.0544 & 0.53 \\
\hline $3-1$ & 0.1540 & 1.51 \\
\hline $1-0.5$ & 0.4908 & 4.81 \\
\hline $0.5-0.25$ & 1.7524 & 17.16 \\
\hline$<0.25$ & 7.7580 & 75.99 \\
\hline Total & 10.2096 & $100 \%$ \\
\hline
\end{tabular}

Table 2. Peat Particle Size Distribution.

\begin{tabular}{|c|c|c|c|c|c|}
\hline No. & $\begin{array}{c}\text { Time } \\
\text { intervals, } s\end{array}$ & $\begin{array}{c}\text { Particle } \\
\text { radius } \\
\text { intervals, } \\
\text { micron }\end{array}$ & $\begin{array}{c}\text { Difference of } \\
\text { sedimentometer } \\
\text { pointer } \\
\text { displacement } \\
\Delta \delta \mathrm{Q}(\mathrm{T}), \mathrm{mm}\end{array}$ & $\begin{array}{c}\text { Particle } \\
\text { content, } \\
\%\end{array}$ & $\begin{array}{c}\text { Conditional } \\
\text { specific surface } \\
\text { area, } \mathbf{c m}^{2} / \mathbf{g}\end{array}$ \\
\hline 1 & \multirow{4}{*}{$\begin{array}{c}\text { Screen } \\
\text { analysis }\end{array}$} & $3500-1500$ & - & 0.53 & 0.5 \\
\hline 2 & & $1500-500$ & - & 1.51 & 1 \\
\hline 3 & & $500-250$ & - & 4.81 & 2 \\
\hline 4 & & $250-125$ & - & 17.16 & 18 \\
\hline 5 & $0.85-3.66$ & $125-50$ & 0.472 & 25.99 & 38 \\
\hline 6 & $3.66-5.76$ & $50-25$ & 0.258 & 19.14 & 48 \\
\hline 7 & $5.76-8.40$ & $25-10$ & 0.218 & 20.86 & 87 \\
\hline 8 & $8.40-10.45$ & $10-5$ & 0.192 & 5.78 & 179 \\
\hline 9 & $10.45-12.76$ & $5-2.5$ & 0.197 & 1.23 & 367 \\
\hline 10 & $12.76-16.43$ & $2.5-1$ & 0.272 & 2.01 & 1084 \\
\hline 11 & $16.43-19.30$ & $1-0.5$ & 0.169 & 0.54 & 1572 \\
\hline 12 & $19.30-\infty$ & $0.5-0.05$ & - & 0.46 & 572 \\
\hline
\end{tabular}


Dry matter loss in a screen analysis makes up $0.59 \%$. The sample party under study consists of coarse and medium dispersed peats being rather uniformed by composition (the coefficient of heterogeneity is $8-48$ ).

The complete dispersion results are shown with the curves of treatment efficiency. The particles 'disappearing' in the treatment are mainly oversize ones. The dependence of the treatment efficiency value $M$ on the content of fractions with less than 250 micron size is close to linear. The inclination of lines depends on the content of fractions whose size is less than 250 microns in the peat stock. The dependence is described with the following equation:

$$
M=\left(0.25+0.021 P_{250}\right) \Delta P_{250}, \%
$$

where $P_{250}$ is the content of fractions with the size of less than 250 microns in the peat stock; $\Delta P_{250}$ is the increment of fractions with the size of less than 250 microns during treatment.

Table 3 shows the computation results and actual data. The squared error of determining the treatment efficiency is less than $3 \%$. Thus, the satisfactory accuracy of the treatment efficiency can be estimated with a screen analysis alone.

Table 3. Comparison of Actual and Estimated Treatment Efficiency.

\begin{tabular}{|c|l|c|c|c|c|}
\hline \multirow{2}{*}{$\begin{array}{c}\text { Sample } \\
\text { No. }\end{array}$} & Treatment & $\begin{array}{c}\text { Actual } \\
\text { treatment } \\
\text { efficiency } \\
\mathbf{M} \text { act, } \mathbf{\%}\end{array}$ & $\begin{array}{c}\text { Content of } \\
\text { fraction } \\
<\mathbf{2 5 0} \mathbf{~ m m ,} \\
\mathbf{\%}\end{array}$ & $\begin{array}{c}\text { Increment } \\
\text { of fraction }< \\
\mathbf{2 5 0} \mathbf{~ m m , ~ \%}\end{array}$ & $\begin{array}{c}\text { Estimated } \\
\text { treatment } \\
\text { efficiency, } \\
\mathbf{\%}\end{array}$ \\
\hline \multirow{3}{*}{ Tank } & untreated & - & 68.11 & 0 & 0 \\
\cline { 2 - 6 } No. 1 & single & 16.1 & 76.36 & 8.25 & 13.8 \\
\cline { 2 - 6 } & three-fold & 21.7 & 80.58 & 12.47 & 21.0 \\
\cline { 2 - 6 } & ten-fold & 29.6 & 86.95 & 18.84 & 31.6 \\
\hline \multirow{3}{*}{ Tank } & untreated & - & 61.50 & 0 & 0 \\
\cline { 2 - 6 } No.2 & ingle & 22.0 & 76.05 & 14.55 & 22.4 \\
\cline { 2 - 6 } & three-fold & 27.8 & 79.10 & 17.60 & 27.1 \\
\cline { 2 - 6 } & ten-fold & 33.8 & 84.59 & 23.09 & 35.6 \\
\hline
\end{tabular}

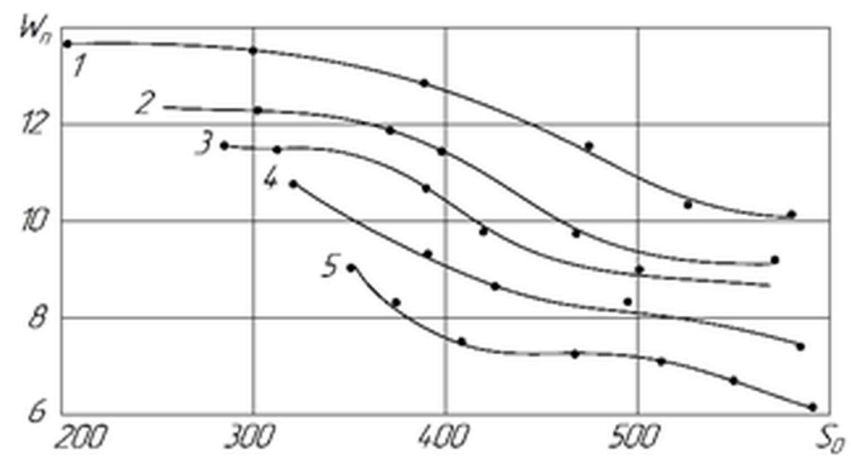

Fig. 1. Dependence of the total moisture capacity $W_{\mathrm{t}}$ on the treatment degree $S_{0}\left(\mathrm{~m}^{2} / \mathrm{kg}\right)$ of magellanicum peat with peat decay degree $\mathrm{R}=15$ (1), 20 (2), 30 (3), 45 (4), 50 (5)\%.

[17] shows that the mechanical effect in an attritor mechanism does not lead to the change of peat structure but the change of its group and chemical composition. For instance, when peat is dispersed, the content of hard-hydrolysable compounds decreases and proves the mechanical destruction of cellulose molecules. 
At the same time the content of reducing substances in a readily hydrolysable fraction increases. The yield of alkaline soluble substances increases by $35 \ldots 70 \%$, that of humic acid increases by $75 \ldots 130 \%$.

It was established experimentally that the active mechanical impact of a screw conveyer on peat generates free associates when larger peat macroaggregates and aggregates break. The number of free functional groups of the associates is larger than that before dispersion.

A water molecule moves wherever free cavities of the same or larger size appear. The number of molecular bonds between peat structure elements increases when peat shrinks and decreases when peat swells.

\section{Results and Discussion}

The representative experiment has shown that the bond has a correlation coefficient of more than 0.9 . For fractions of $<10$ microns the square error makes up $6.6 \%$, and for fractions of $<1$ micron it makes up $4.1 \%$. Thus, the content of fine-dispersed and colloidal fractions can be determined with the adequate accuracy by the screen analysis alone.

The value of the conditional specific surface area depends on fractioning the dispersion system and, therefore, it is conditional. The specific surface area was estimated with the scale of detailed fractioning. The largest part of the surface is covered with colloidal fraction (the size being less than 1 micron). Thus, the presence of a nearly linear bond can be expected between the fraction of $<1$ micron and the conditional specific surface area.

According to the data of Figure 1 mechanical treatment influences the values of total moisture capacity, with the relationship being nonlinear. The values of total moisture capacity up to $S_{0}=350 \mathrm{~m}^{2} / \mathrm{kg}$ decrease insignificantly owing to partial grinding of fibrous coarse fractions.

The mechanical treatment up to $S_{0}=500 \mathrm{~m}^{2} / \mathrm{kg}$ causes the sharp decrease of total moisture capacity due to practically complete destruction of coarse-dispersed fractions. The third site of $S_{0}>500 \mathrm{~m}^{2} / \mathrm{kg}$ shows that the values of total moisture capacity change insignificantly. A somewhat different relationship under study can be seen for the peat of high decay degree (Fig. 1, Curves 4 and 5). We can locate only two sites where the value of total moisture capacity decreases sharply at first and then changes slightly depending on its dispersion degree. Water physical peat properties change at the colloidal fraction level. Therefore, the change of total moisture capacity must result in varying parameters of structure formation.

Highbog peat with $50 \%$ decay degree of and treatment $S_{0} \approx 500 \mathrm{~m}^{2} / \mathrm{kg}$ gives Curve 5 decreasing gradually. Then the moisture capacity decreases significantly, with the dispersion changing insignificantly. To get at least little dispersion increment the material under study is repeatedly treated on a screw conveyer adjusted with additional blades and screens.

The research analysis shows that it is not correct to compare peat samples by their dispersion degree since the materials with the known-good different physical and chemical composition are compared. That is why general parameters should be introduced to characterize peat structural and physical-chemical properties.

Multiple peat treatment causes its mechanical consolidation when the content of fibrous coarse fractions decreases and the number of fine-dispersed fractions increases significantly. At that a huge amount of weakly bound moisture is released and transformed into capillary one. This increases plasticity and improves peat deformation properties.

\section{Conclusion}

The most significant issues of dispersion consist in the presence of a coarse-dispersed, especially fibrous (fractions $>250$ microns), and fine-dispersed ( $<10$ microns) fractions. The 
final state of the treatment process is characterized by the fact that the bigger the total pan accumulation is, the bigger is the accumulation of particles in the fine-dispersed area. When the accumulations of less than 250 micron fractions are similar, that of fine-dispersed fractions is higher if the available total is bigger. That is why the rate of fine-dispersed fraction accumulation is proportional to the rate of pan (less than 250 microns) accumulation and the available total of fine-dispersed fractions.

Thus, the mechanical treatment of peat does not only change its structural-mechanical but physical-chemical properties. The value of total moisture capacity can be used as one of the basic indicators determining the combination of various characteristics of raw peat and finished products.

\section{References}

1. S. N. Gamayunov, O. S. Misnikov, IFZh, 71:2, 233-234, (1998)

2. V. Lebedev, O. Puhova E3S Web of Conf., 15, 01018, (2017)

3. O. S. Misnikov, A. E. Afanas'iev, Theoretical Foundations of Chemical Engineering, 37:6, 582-589, (2003)

4. O. S. Misnikov, E. Yu. Chertkova, Eurasian Mining, 1 (21), 63-68, (2014)

5. O. Misnikov, V. Ivanov, E3S Web of Conf., 15, 01017 (2017)

6. O. S. Misnikov, O. V. Dmitriev, E. Yu. Chertkova, Eurasian Mining, 2:24, 30-34, (2015)

7. O. Misnikov, E3S Web of Conf., 21, 01020, (2017)

8. O. Misnikov, Polymer Science. Series D, 7:3, 252-259, (2014)

9. O. Misnikov, Mires and Peat, 18:22, 1-15, (2016)

10. O. S. Misnikov, O. V. Dmitriev, V. I. Popov, E. Yu. Chertkova, Polymer Science. Series D, 9:1, 133-139, (2016)

11. O. S. Misnikov, I. O. Korolev, Polymer Science. Series D, 10:3, 255-259, (2017)

12. O. Misnikov, A. Timofeev, O. Pukhova, Polymer Science. Series D, 8:1, 66-74, (2015)

13. E. A. Kremcheev, D. A. Kremcheeva, Journal of Industrial Pollution Control, 33:1, 787791, (2017)

14. E. A. Kremcheev, D. A. Kremcheeva, Indian Journal of Science and Technology, 9:12, 89525, (2016)

15. E. A. Kremcheev, D. O. Nagornov, Ecology, Environment and Conservation, 23:2, 956965, (2017)

16. E. A. Kremcheev, D. A. Kremcheeva. Research Journal of Pharmaceutical, Biological and Chemical Sciences, 7:3, 1284-1289, (2016)

17. A. E. Afanas'iev, S. N. Gamayunov O. S. Misnikov, Colloid Journal, 61:3, 274-279, (1999) 